\title{
Psychosocial aspects of diabetes in pregnancy
}

\author{
Bharti Kalra, Yatan Pal Singh Balhara ${ }^{1}$, Sanjay Kalra ${ }^{2}$ \\ Department of Gynaecology, Bharti Hospital and B.R.I.D.E., Karnal, ${ }^{1}$ Psychiatry, National Drug Dependence Treatment Centre, All India \\ Institute of Medical Sciences, New Delhi, ${ }^{2}$ Endocrinologist, Bharti Hospital and B.R.I.D.E., Karnal, India
}

\section{A B S T R A C T}

Recent guidelines promote a patient-centered approach to the management of diabetes. The relevance of the bio-psycho-social model or holistic approach has also been explored in women's health. Specifically, psychosocial and psychiatric morbidity has been appreciated and analyzed in pregnancy and the postpartum period. However, minimal attention has been focused on the psychosocial and social factors that impact pregnancy complicated by diabetes. This is even more surprising from a South Asian perspective, where deep-rooted sociocultural mores create a milieu that may not be very friendly to the antenatal woman with diabetes. This review discusses the psychosocial issues relevant in the context of pregnancy among diabetics. An approach to address these issues has also been highlighted.

Key words: Diabetes mellitus, pregnancy, psychosocial issues

\section{INTRODUCTION}

Recent guidelines promote a patient-centered approach to the management of diabetes, ${ }^{[1]}$ arguing the case for shared decision making as the basic framework of diabetes care. They highlight the need to assess various factors related to the patient and his or her surroundings while determining glycemic strategies and targets.

This approach forms part of a holistic management, which in turn is based upon an in-depth understanding of the bio-psycho-social model of health. ${ }^{[2]}$ The bio-psycho-social model, postulated by Unger and colleagues, proposes that not only biological but also psychosocial and social factors influence the state of health. Much work and debate has been carried out regarding the importance of psychosocial factors in diabetes, ${ }^{[3]}$ which is arguably a perfect example of a bio-psycho-social health condition.

\begin{tabular}{|l|l|}
\hline \multicolumn{2}{|c|}{ Access this article online } \\
\hline Quick Response Code: & Website: \\
\hline & www.josh.net \\
\cline { 2 - 2 } & \\
\hline
\end{tabular}

In a separate vein, the relevance of the bio-psycho-social model or holistic approach has also been explored in women's health. ${ }^{[4]}$ The overlap between diabetes and women's health has been discussed from a South Asian perspective as well. ${ }^{[5]}$

Specifically, psychosocial and psychiatric morbidity has been appreciated and analyzed in pregnancy and the postpartum period. Postpartum psychosis, for example, is a well-known entity. ${ }^{[6]}$ Thus, both diabetes and pregnancy are associated with, and influenced by, psychosocial issues.

Surprisingly, however, minimal attention has been focused on the psychosocial and social factors that impact pregnancy complicated by diabetes. This is even more surprising from a South Asian perspective, where deep-rooted sociocultural mores create a milieu that may not be very friendly to the antenatal woman with diabetes. ${ }^{[5]}$

This review discusses the psychosocial issues relevant in the context of diabetes in pregnancy.

\section{Preconception phase}

The preconception phase in women with preexisting type 1 and type 2 diabetes is marked by fear and concern.

Corresponding Author: Dr. Yatan Pal Singh Balhara, Assistant Professor of Psychiatry, National Drug Dependence Treatment Centre (NDDTC), All India Institute of Medical Sciences (AlIMS), New Delhi - 110 029, India. E-mail: ypsbalhara@gmail.com 


\section{Psychological factors}

The main fear during the preconception phase is that of subfertility or infertility (unpublished data). This is true for both women with type 1 diabetes, who may have coexisting endocrine anomalies such as thyroid dysfunction, and for those with type 2 diabetes, who may have polycystic ovarian syndrome (PCOS) and/or hypothyroidism, which also contribute to subfertility. Another concern is the fear for the health of the unborn child. These psychological factors may be exacerbated by an unfavorable social environment and medical or health care system.

\section{Social factors}

In a traditional Asian family, there is immense pressure upon the newly weds to produce children. The pressure is enhanced if the couple, especially the mother-to be, has a medical condition such as diabetes. The bulk of this social pressure is directed toward, and faced by, the woman, whose psychological health is impacted further.

\section{Health care system}

At times, the health care system may worsen the psychological health of women who are planning a pregnancy. Few integrated centers exist that provide the services of an obstetrician, an endocrinologist, a diabetes educator and a psychologist in one team. Various mental health issues may not be adequately addressed during the preconception counseling (PCC), and referral to a qualified mental health professional is uncommon. The existing health care systems also do not encourage family-oriented therapy, which includes the spouse (husband) and mother-in-law (in the Indian context) as essential partners in the preconception process.

\section{Antenatal phase}

The antenatal phase is a time of great psychological and social stress for the women with diabetes. Dysglycemia adds an extra psychological load to various other discomforts, burdens and challenges.

\section{Psychological factors}

The antenatal period brings with it various psychological stresses that can be classified as in Table 1. The psychosocial concerns of antenatal women with diabetes can be classified into three clusters or themes [Table 1]. Fear for the unborn child, fear for one self and fear related to the family/social issues are three family major issues faced by these patients as well as their close family members such as husbands. Fear for the unborn child is the main concern of the antenatal mothers, with fear for their own medical and obstetric health also contributing to psychological stress. Fears revolve around immediate adverse events such as congenital anomalies and pregnancy loss, shortterm events such as mode of delivery and neonatal health and remote issues like the possibility of the unborn child developing diabetes.

Unpublished data from Karnal, Haryana, reveal that while women are concerned mainly about the health of the unborn child, their husbands face equal stress related to the health of their spouse as well as the unborn child.

\section{Social factors}

Social systems, which discriminate against people with diabetes and which may discriminate against women, reach their nadir when it comes to women with diabetes. There are no social knowledge systems in place to provide appropriate care to an antenatal woman with diabetes. Well-meaning relatives may create unnecessary stress by referring to the possible complications of diabetes and negatively impact the wellbeing of the woman. Lack of understanding about correct nutrition and physical activity worsens the situation.

\section{Health care system}

The health care system may not facilitate smooth obstetricendocrine teamwork, as both specialties remain busy with heavy morbidity. In women with pregnancy, a multidisciplinary effort is required, which needs the services of an obstetrician, an endocrinologist, a diabetes educator and a psychologist, preferably under one roof. This is often

\begin{tabular}{|c|c|c|}
\hline \multicolumn{3}{|c|}{$\begin{array}{l}\text { Table 1: Psychosocial concerns in pregnancy complicated } \\
\text { by diabetes }\end{array}$} \\
\hline $\begin{array}{l}\text { Fear for } \\
\text { self }\end{array}$ & Medical health & $\begin{array}{l}\text { Fear of medical } \\
\text { complications of diabetes } \\
\text { Fear of insulin } \\
\text { Fear of permanent } \\
\text { dependency on insulin }\end{array}$ \\
\hline & Obstetric health & $\begin{array}{l}\text { Fear of obstetric } \\
\text { complications, eg, preterm } \\
\text { delivery, high blood pressure } \\
\text { Fear of caesarian section }\end{array}$ \\
\hline & Nutritional health & $\begin{array}{l}\text { Fear of not being allowed } \\
\text { to eat properly }\end{array}$ \\
\hline \multirow[t]{3}{*}{$\begin{array}{l}\text { Fear } \\
\text { related } \\
\text { to family }\end{array}$} & Social health (fear of stigma) & $\begin{array}{l}\text { Fear of lack of acceptance } \\
\text { by in-laws } \\
\text { Fear of blame being placed } \\
\text { on parents }\end{array}$ \\
\hline & Emotional health & $\begin{array}{l}\text { Fear of lack of acceptance } \\
\text { by husband } \\
\text { Fear of lack of attractiveness } \\
\text { to husband }\end{array}$ \\
\hline & Financial health & Fear of extra expenses \\
\hline \multirow{5}{*}{$\begin{array}{l}\text { Fear for } \\
\text { unborn } \\
\text { child }\end{array}$} & \multicolumn{2}{|l|}{ Fear of pregnancy loss } \\
\hline & \multicolumn{2}{|l|}{ Fear of congenital malformation } \\
\hline & \multicolumn{2}{|c|}{ Fear of need for admission in nursery } \\
\hline & \multicolumn{2}{|c|}{ Fear of insulin requirement in childhood } \\
\hline & \multicolumn{2}{|l|}{ Fear of diabetes in later life } \\
\hline
\end{tabular}


not available and results in unnecessary fatigue for the patient, who has to visit multiple care providers.

\section{Postpartum phase}

The psychosocial factors that influence diabetes do not cease acting once the pregnancy has been completed. If at all, these factors become more prominent.

\section{Psychological factors}

Even after completion of normal pregnancy, not complicated by diabetes, women experience transient symptoms of depression. Whether this is more common in women with gestational diabetes mellitus or in women with persisting diabetes is not yet known. In their experience, however, the authors have not come across any women with diabetes who has required hospitalization for postpartum depression.

Extreme fluctuations in insulin requirement soon after delivery because of the changing physiological milieu, altered diet patterns and changes in physical activity may be linked with fluctuations in mood as well.

\section{Social factors}

Successful childbirth is a time for celebration and food is an integral part of all celebrations. Women with diabetes, therefore, are plied with various foods, almost all of which are calorie dense.

Examples of some harmful postpartum nutritional practices prevailing in north India include the consumption of large amounts of ghee (clarified butter), panjiri (a powdered mixture of ghee, sugar and wheat flour), sweet meats and dry fruits. Although these foods do provide the muchneeded energy, overenthusiastic consumption can lead to poor glycemic control. Contributing to this carefree attitude is the perception that diabetes in pregnancy is a "temporary" phenomenon that resolves with delivery and needs no further follow-up.

\section{Psychiatric factors}

Postpartum depression is a distinct condition reported in up to $10 \%$ of all pregnancies. This is characterized by a sudden onset of the cardinal symptoms of depressionloss of interest and anhedonia - after delivery. Postpartum depression is more common in mothers with a past history of depression or affective disorders, single mothers, young mothers, smokers, drug users and in those with a history of hyperemesis gravidarum. ${ }^{[6]}$ A simple screening tool that can be used is the Whooley's two-question case-finding instrument, ${ }^{[7]}$ while a diagnostic tool specific for the postnatal period is the Edinburgh Postnatal Depression Score. ${ }^{[8]}$
A rare, but more severe, mental illness that may occur in women after delivery is puerperal psychosis. ${ }^{[6]}$ This is more often seen in women with a past history of psychiatric disorders. While diabetes is not listed as a known predisposing factor for either depression or psychosis in the postpartum period, the evidence linking these conditions in the general population is too strong to be ignored. One must, therefore, screen women with diabetes carefully for symptoms or signs of psychological or psychiatric ill health.

\section{Impact on health}

Psychosocial issues have an impact not only on maternal health but also on the health of the unborn fetus. Maternal exposure to grief or bereavement immediately before or during pregnancy is linked to a greater risk of unborn children developing diabetes, both type $1^{[9]}$ and type $2^{[10]}$, later on in life. The strongest association for type- 1 diabetes among children is found in the offspring of mothers exposed to traumatic father or sibling deaths; the association is stronger for girls. In relation to the development of type 2 diabetes, these findings are most pronounced when bereavement is caused by the death of an elder child. Reports also indicate the second trimester of pregnancy to be the most sensitive period of bereavement exposure. ${ }^{[10]}$ This may be explained by the lack of maturity of placental II ß-hydroxysteroid dehydrogenase until 20-24 weeks of gestation. This enzyme functions to prevent excess maternal adrenal steroids, such as cortisol, from reaching the fetal circulation. Lack of, or inactivity of, this enzyme may allow fetal hypercortisolemia, which may negatively impact fetal hepatic and pancreatic growth or function at critical times of organogenesis. ${ }^{[11]}$

Presents an outline of framework for identifying the relevant psychological, social and psychiatric aspects relevant to diabetes care in pregnancy.

\section{Management}

\section{History taking}

The first step in managing psychosocial issues is to ask about them. This "asking" or history taking should be done in a sensitive, empathic manner, while respecting the privacy and dignity of the patient. The acronym CARES, ${ }^{[12]}$ which has been coined to describe the qualities of a good diabetes counselor, holds true for every diabetes care provider. Another acronym, WATER, ${ }^{[13]}$ created to describe an abbreviated form of motivational interviewing, is useful in explaining the way an ideal conversation should take place between a provider and a patient [Table 2]. Yet another aid to good clinical practice is the Hierarchy of Questioning ${ }^{[14]}$ concept, which emphasizes moving from non-threatening to threatening questions or queries. 


\begin{tabular}{|c|c|c|}
\hline \multicolumn{3}{|c|}{ Table 2: The WATER approach } \\
\hline W & Welcome warmly & Body language \\
\hline & & The OPD encounter \\
\hline A & Ask and assess & $\begin{array}{l}\text { Identifying and using cues } \\
\text { (internal, external*, laboratory) } \\
\text { Hierarchy of questioning } \\
\text { The insulin encounter }\end{array}$ \\
\hline $\mathrm{T}$ & Tell truthfully & $\begin{array}{l}\text { Mid-sentence analysis } \\
\text { (verbal/nonverbal cues) } \\
\text { Analogy building }\end{array}$ \\
\hline $\mathrm{E}$ & Explain with empathy & $\begin{array}{l}\text { Examples/experience sharing } \\
\text { Demonstration } \\
\text { Coping skills training }\end{array}$ \\
\hline $\mathrm{R}$ & Reassure and return & $\begin{array}{l}\text { Prochaska's theory of motivation } \\
\text { Minimizing discomfort of change } \\
\text { Working the environment } \\
\text { (ecosensitivity) }\end{array}$ \\
\hline
\end{tabular}

Specific to pregnancy complicated by diabetes is a Triage system. This is helpful in busy obstetric or diabetes clinics, and helps the health care provider in decision making related to which patients to spend more time upon. Patients who are not able to achieve good glycemic control, without any obvious cause, must be questioned about psychosocial issues. On the other hand, women with good control may not need a detailed psychological history taking. In patients who are identified as possibly having latent, unaddressed, potentially damaging psychosocial concerns, a step-wise approach to diagnosis is indicated. The first psychosocial domain to be explored is that of fear for the unborn child. If one is able to build a strong rapport with the patient, one can move on to discussing fear for one self. Family-related issues should be explored only after having built trust and gained confidence of the patient.

\section{Preconception counseling}

PCC is an essential part of obstetric medicine, especially for women with diabetes. This should not be limited, however, to the biological aspects of care. PCC should include an assessment of the women's emotional psychology and social health $\mathrm{A} 360^{\circledR}$ assessment, including opinions from her husband and family (especially the mother-in-law), should be sought. A detailed analysis of her unspoken fears and concerns, such as infertility, congenital malformations and adverse obstetric outcomes, must be carried out. This will help allay unwarranted anxiety.

\section{Support}

Empathic listening and providing an opportunity for catharsis are simple yet effective ways of providing psychological support to antenatal women with diabetes.

Formal cognitive behavioral therapy or relaxation therapy may be required for some patients. Such therapy is best provided by experienced, qualified mental health professionals. However, the principles of behavioral therapy and relaxation therapy can be used by diabetes care professionals to achieve better emotional health in their patients.

Medicines are also required in certain cases to address these mental health issues. However, the role of medicines in the management of these issues is beyond the scope of this review.

\section{Glycemic control}

The need for glycemic control should not be forgotten while managing psychosocial issues. Poor glycemic control per se has been noted to be linked with depression. At times, however, especially in the North West Indian context, certain strategies for glycemic control may create more stress than benefit. A newly married woman, for example, with a family history of diabetes, diagnosed to have diabetes mellitus and prescribed an intensive insulin regime, may be labeled as having preexisting diabetes mellitus by her in-laws. This may lead to unwanted social pressures and ostracization or stigmatization by the family.

Such a situation can be avoided by using softer terminology for the diagnosis (impaired glucose tolerance, for example) and by using oral hypoglycemic drugs such as metformin, if deemed appropriate.

Medical nutrition therapy should be prescribed in a manner that does not radically modify the normal dietary pattern of the family. To ask the family to shift from a ricebased to a wheat-based diet, just because one member has diabetes, for example, will create stress and dysglycemia instead of solving the problem. It is more prudent to encourage small, but multiple, changes in a step-wise manner in order to minimize the discomfort of change.

One should realize the financial burden of various foodstuffs apart from prescribing a diet. Suggesting difficult-to-procure, expensive, processed food items may unnecessary burden a family; when easily available, local produce can suffice.

A similar approach should be followed for physical activity. Whatever exercise regimes are suggested should be in concordance not only with the physical health of the woman but also with the prevailing social and cultural mores.

\section{The family and mother-in-law}

No write up on psychological factors in pregnancy will be complete without a mention of the role of the family, 
especially women members, usually led by the motherin-law.

The family is a source of support and, paradoxically, stress as well. The Indian mother-in-law fulfills multiple roles and responsibilities toward her son, daughter-in-law and (unborn) grandchildren. Her support provides a safe and comforting ambience for the daughter-in-law, who is expected to fulfill her duty of producing a (male) heir for the family. She ensures a healthy (as per her knowledge and attitudes) lifestyle including diet, physical activity and stress management for her daughter-in-law before, during, and after pregnancy.

The mother-in-law's knowledge, attitudes and practices, however, are based on traditional folklore, and may clash with modern medicine. This is especially true in the case of pregnancy complicated by diabetes.

For example, the need for moderation in diet, such as cooking oil and fat restriction, may not be understood. Similarly, the need for small, frequent meals, in a $3+3$ meal pattern, may be frowned upon. Medical advice to restrict physical activity in pregnancies complicated by diabetes is often not appreciated. The logic of avoiding prenatal stress and grief may not be internalized either.

Some traditional practices, which are harmful to women with diabetes, may be propagated actively by the well-meaning but ill-informed mother-in-law. These include liberal intake of ghee (clarified butter) in the last trimester, thought to facilitate normal vaginal delivery, and observance of various fads in an effort to ensure a healthy offspring. Other errors of omission include avoiding certain fruits as they are considered to be abortifacients.

The mother-in-law should not be perceived as a fountain head of evil. Her active participation can be ensured by proactively seeking her attendance in the preconception and antenatal counseling sessions and clinic visits. This praxis brings about a sense of empowerment in the motherin-law and includes her in the process of shared decision making. This allows more optimal translation of theory into practice in the domestic environment, with resultant benefits for both the mother and the child.

A seemingly innocuous prescription, such as shifting from oral antidiabetic drugs (OADs) to insulin for example, will meet with greater acceptance if it is announced through the mother-in-law:
"We suggest that she goes on insulin for a short period of time, to ensure a healthy outcome of her pregnancy. Please help us motivate her."

\section{REFERENCES}

1. Inzucchi SE, Bergenstal RM, Buse JB, Diamant M, Ferrannini E, Nauck $M$, et al. Management of hyperglycaemia in type 2 diabetes: A patient-centered approach. Position statement of the American Diabetes Association (ADA) and the European Association for the Study of Diabetes (EASD). Diabetologia 2012;55:1577-96.

2. Engel GL. The need for a new medical model: A challenge for biomedicine. Science 1977;196:129-36.

3. Das S, Kalra S. Diabetes: Exploring social and psychological domain. J Soc Health Diabetes 2013;1:1-2.

4. Kalra B, Agarwal S, Magon S. Holistic care of menopause: Understanding the framework. J Midlife Health 2012;3:66-9.

5. Bajaj S, Jawad F, Islam N, Mahtab H, Bhattarai J, Shrestha D, Wijeyaratne C, Muthukuda D, Widanage N, Aye T, Aung M, Kalra B, Anjana R, Sreedevi A and Verma K. South Asian women with diabetes: Psychosocial challenges and management: Consensus statement. Indian J Endocr Metab 2013;17:548-62.

6. Sharma JB. Textbook of Obstetrics. New Delhi: Avichal Publishing Co.; 2012.

7. Whooley MA, Avins AL, Miranda J, Browner WS. Case-finding instruments for depression. Two questions are as good as many. J Gen Intern Med 1997;12:439-45.

8. Cox JL, Holden JM, Sagovsky R. Detection of postnatal depression. Development of the 10-item Edinburgh Postnatal Depression Scale. Br J Psychiatry 1987;150:782-6.

9. Virk J, Li J, Vestergaard M, Obel C, Lu M, Olsen J. Early life disease programming during the preconception and prenatal period: Making the link between stressful life events and type-1 diabetes. PLoS One 2010;5:e11523.

10. Li J, Olsen J, Vestergaard M, Obel C, Kristensen JK, Virk J. Prenatal exposure to bereavement and type-2 diabetes: A Danish longitudinal population based study. PLoS One 2012;7:e43508.

11. McTernan CL, Draper N, Nicholson H, Chalder SM, Driver P, Hewison M, Kilby MD and Stewart PM. Reduced placental 11 betahydroxysteroid dehydrogenase type 2 mRNA levels in human pregnancies complicated by intrauterine growth restriction: An analysis of possible mechanisms. J Clin Endocrinol Metab 2001;86:4979-83.

12. Kalra S, Kalra B. A Good diabetes counsellor 'cares': Soft skills in diabetes counselling. Int J Health 2010;11.

13. Kalra S, Kalra B, Sharma A, Sirka M. Motivational interviewing: The WATER approach. Endocr J 2010;57:S391.

14. Kalra S, Balhara Y, Baruah M, Saxena A, Makker G, Jumani D, Kochhar K, Majumdar S, Agrawal N and Zaveri H. Consensus guidelines on male sexual dysfunction. J Med Nutr Nutraceut 2013;2:5-18.

How to cite this article: Kalra B, Balhara YS, Kalra S. Psychosocial aspects of diabetes in pregnancy. J Soc Health Diabetes 2014;2:25-9.

Source of Support: Nil. Conflict of Interest: None declared. 